\title{
Insulin-like Growth Factor-1 Enhances Ventricular Hypertrophy and Function during the Onset of Experimental Cardiac Failure
}

\author{
Robert L. Duerr, * Samuel Huang, ${ }^{*}$ Hamid R. Miraliakbar, ${ }^{*}$ Ross Clark," Kenneth R. Chien, ${ }^{* \star \$}$ and John Ross, Jr. ${ }^{* \$}$ \\ Division of Cardiology, *Department of Medicine, ${ }^{\ddagger}$ Center for Molecular Genetics, and ${ }^{\S}$ The American Heart Association-Bugher \\ Foundation Center for Molecular Biology, University of California San Diego, San Diego, California 92093; and "Genentech, Inc., \\ South San Francisco, California 94080
}

\section{Abstract}

To determine whether additional hypertrophy would be beneficial or maladaptive in cardiac failure, the effects of insulin-like growth factor (IGF-1) were investigated in rats with left ventricular (LV) dysfunction. In normal rats, 3 $\mathrm{mg} / \mathrm{kg}$ per d of recombinant human IGF-1 for $14 \mathrm{~d}$ augmented LV wt $(32 \%)$ and increased $L V /$ body wt ratio $(P$ $<0.01) .2 \mathrm{~d}$ after coronary occlusion, rats were randomized to IGF-1 (3 mg/kg per d) or placebo. After 2 wk, IGF-1treated rats showed significant increases in $\mathrm{LV}$ wt (13\%) and $L V$ wt/tibial length ratio, but $L V /$ body wt ratio was unchanged. By microangiography, compared with controls $(n=12)$ IGF-1-treated rats $(n=16)$ showed increased LV end-diastolic volume (19\%) and stroke volume (31\%) (both significant normalized to tibial length, but not to body wt). Average infarct size did not differ between groups. The LV ejection fraction (EF) was not significantly different between groups, but estimated cardiac output was higher in treated rats; there was a significant interaction for the EF between infarct size and treatment $(P=0.029)$ and a trend for EF to be higher in treated rats with large infarctions (EF 33.4 vs $25.1 \%$ in controls). Myocyte cross-sectional areas in noninfarcted $\mathrm{LV}$ zones tended to be larger in treated rats (232.1 vs $\left.205.4 \mathrm{\mu m}^{2} ; P=0.10\right)$, but there was no difference in capillary density and collagen content did not differ between groups. In conclusion, IGF-1 administration caused hypertrophy of the normal heart in vivo. When stimulated by IGF-1, the severely dysfunctional heart in evolving myocardial infarction is capable of undergoing additional hypertrophy with evidence of improved function, suggesting a beneficial effect. Further investigation of the potential role of growth factor therapy in heart failure appears warranted. (J. Clin. Invest. 1995. 95:619-627.) Key words: insulin-like growth factor-1 - cardiac hypertrophy • left ventricular remodeling $\bullet$ myocardial cell size $\bullet$ collagen

\section{Introduction}

Identification of the molecular determinants of cardiac failure is a problem of major importance to cardiovascular biology and

Address correspondence to John Ross, Jr., M. D., University of California, San Diego, Department of Medicine 0613B, 9500 Gilman Drive, La Jolla, CA 92093-0613. Phone: 619-534-3347; FAX: 619-534-1626. 1994.

Received for publication 4 May 1994 and in revised form 25 August

J. Clin. Invest.

(c) The American Society for Clinical Investigation, Inc.

0021-9738/95/02/0619/09 \$2.00

Volume 95, February 1995, 619-627 medicine. One of the earliest events during the pathological remodeling which accompanies heart failure is enlargement of the cardiac chambers, generally considered an initial compensatory response. Progressive ventricular dilation then ensues, sometimes associated with cell loss (1), and relative wall thinning occurs which inevitably leads to increased wall stress with afterload mismatch and reduced cardiac output (2). Although the structure of failing myocardium varies widely, enlargement of individual cardiac muscle cells almost invariably accompanies myocardial injury in a wide variety of disorders and is a central feature of the failing heart phenotype $(1,3,4)$. The clinical utility of angiotensin converting enzyme inhibitors to prolong survival in patients with heart failure (5) and their reported ability to block in vivo hypertrophy in several experimental settings (6-8) have led to the view that activation of cardiac hypertrophy is an unfavorable component of pathological remodeling of the ventricular chamber. As a result, the inhibition of ventricular chamber enlargement and hypertrophy has become one therapeutic target for new molecular strategies to improve and/or maintain cardiac function after myocardial injury (9).

An alternative approach would be to stimulate the development of more adequate, physiological compensatory hypertrophy. Recent advances in the development of in vitro and in vivo systems for analyzing the signaling pathways for cardiac hypertrophy (10-17) suggest that there may be distinct programs which dictate physiological and pathological forms of cardiac muscle hypertrophy (10). Therefore, appropriate biological targets for maintaining cardiac function in the setting of heart failure might include not only agents designed to block pathological forms of hypertrophy, such as angiotensin converting enzyme inhibitors, but also the development of new approaches to promote physiological forms of hypertrophy which might lead to maintenance or improvement of cardiac function; moreover, novel and/or known growth factors might mediate either pathological or physiological forms of hypertrophy through the activation of differing subsets of cardiac muscle genes, depending upon the in vivo setting (9).

Several independent lines of evidence suggest that insulinlike growth factor-1 (IGF-1) may be involved in mediating physiological forms of cardiac hypertrophy. IGF-1 is a 70-amino acid basic peptide (18) which produces many of the effects of growth hormone $(\mathrm{GH})^{1}$ and has growth-promoting actions on a variety of tissues including the heart (19-21). Using a cultured neonatal rat myocardial cell system of hypertrophy, which has been extensively characterized to monitor the effects of defined hormonal and peptide-derived stimuli $(10-14,17)$, IGF-1 has been shown

1. Abbreviations used in this paper: $\mathrm{EF}$, ejection fraction; $\mathrm{GH}$, growth hormone; LV, left ventricular; LVEDV, LV end-diastolic volume; LVESV, LV end-systolic volume; SV, stroke volume. 
to activate several features of the hypertrophic response, including the upregulation of MLC-2v and troponin I gene expression $(22,23)$. Rats undergoing left ventricular (LV) hypertrophy by several mechanisms have an associated increase in IGF-1 mRNA and protein levels within the myocardium coincident with the development of hypertrophy $(24,25)$. Therefore, IGF-1-dependent signaling pathways may be important in the initiation of the in vivo hypertrophic response, possibly via autocrine or paracrine mechanisms. Also, homozygous IGF-1-deficient gene-targeted mice display defects in cardiac myogenesis indicating a role for this growth factor in development $(26,27)$. GH, the major stimulus for IGF-1 production and release, can induce cardiac enlargement in experimental animals, without signs of cardiomyopathy by histological analysis or evidence of a failing heart phenotype (28). Adult humans with GH deficiency display slight basal cardiac dysfunction and decreased LV mass (29), which are reversed by 6 mo of GH replacement therapy (30). In clinical acromegaly of many years duration, LV size and wall thickness are increased, along with augmented plasma volume, increased stroke volume, and normal to elevated cardiac index $(31,32)$, and in a minority of patients heart failure occurs, typically with a normal cardiac index (32). Many of the above observations suggest the possibility that IGF-1 may be a candidate gene and growth factor for the activation of signaling pathways for hypertrophy of the myocardium, but to date there is no direct evidence that IGF-1 can activate a hypertrophic response in vivo.

The availability of recombinant IGF-1 allows a direct test of the potential therapeutic role of activating physiological forms of hypertrophy in the setting of ventricular remodeling after cardiac injury. Therefore, this study was designed to examine in vivo the effects of purified recombinant IGF-1 in the normal heart and in the setting of pathological remodeling using a well-characterized post-myocardial infarction model in the rat. Function in the intact heart was assessed using a newly developed method of digitized microangiography. The administration of IGF-1 resulted in ventricular chamber enlargement and hypertrophy, accompanied by evidence of enhanced cardiac performance, suggesting that the activation of a physiological hypertrophic response during the onset of experimental heart failure in the setting of myocardial infarction may be beneficial.

\section{Methods}

Animals were handled according to the animal welfare regulations of the University of California San Diego, and the experimental protocol was approved by the Animal Subjects Committee of this institution.

\section{Dose responses to IGF-1 in normal rats}

To determine the optimum dose of IGF-1, 23 normal female SpragueDawley rats were treated with increasing doses of recombinant human IGF-1 (Genentech Inc., South San Francisco, CA). Human IGF-1 is identical to rat IGF-1 in 67 of 70 residues (33). Treatment groups were: placebo (sodium citrate buffer); $1 \mathrm{mg}$ IGF-1/kg per d for $14 \mathrm{~d} ; 2.2 \mathrm{mg}$ IGF-1/kg per $\mathrm{d}$ for $25 \mathrm{~d}$; $3 \mathrm{mg}$ IGF-1/kg per $\mathrm{d}$ for $14 \mathrm{~d} ; n=5-6$ per group. Osmotic pumps (Alzet, Palo Alto, CA) were implanted in the peritoneal cavity to infuse the above doses over the defined periods, based on the animal's weight at pump implantation. At the end of the infusion, the animals were killed and body weight, heart weight, organ weights, and tibial length were measured.

\section{Animal model of myocardial infarction}

Female Sprague-Dawley rats weighing 250-300 g were anesthetized with a mixture of ketamine hydrochloride $(100 \mathrm{mg} / \mathrm{kg})$, xylazine (10 $\mathrm{mg} / \mathrm{kg}$ ), and morphine sulfate $(5 \mathrm{mg} / \mathrm{kg}$ ) all given intraperitoneally (i.p.). Complete occlusion of the left coronary artery was performed as described elsewhere (34). Briefly, after anesthesia, animals were placed in the supine position, intubated, and ventilated under positive pressure with a rodent ventilator (model 683; Harvard Apparatus, Inc., South Natick, MA). Under a dissecting microscope, a left thoracotomy was performed in the fourth intercostal space, the pericardium was opened, and the left coronary artery (which is intramural) was encircled within the myocardium between the left atrial appendage and the right ventricular outflow tract with a curved needle and 6-0 silk suture. Upon trying the ligature, complete occlusion was evidenced by a distinct color change of the myocardium together with the appearance of acute ST segment elevation on the electrocardiogram (ECG). The chest was then closed in layers and the pneumothorax was evacuated.

\section{EXPERIMENTAL PROTOCOL}

After surgery, animals were caged in proportion to size, given water and standard rat chow ad libitum, and housed in a climate-controlled environment subjected to 12-h light/dark cycles. Of the 93 operated animals, $59(63 \%)$ survived to the second postoperative day, when 40 animals which showed ECG evidence of infarction were randomly assigned to IGF-1 or vehicle. Animals were anesthetized (ketamine hydrochloride, $100 \mathrm{mg} / \mathrm{kg}$; xylazine, $10 \mathrm{mg} / \mathrm{kg}$, i.p.), placed in the supine position, a $1-\mathrm{cm}$ midline incision made in the abdominal wall, and an osmotic pump implanted in the peritoneal cavity. Based on the data in normal rats, pumps delivered either $3 \mathrm{mg}$ IGF-1/ $\mathrm{kg}$ per $\mathrm{d}$ (weight on that day) or sodium citrate buffer for $2 \mathrm{wk}$. The peritoneal cavity was then closed in layers.

Heart rates and indirect systolic blood pressures were measured in the conscious state $9 \mathrm{~d}$ after randomization by the unheated tail cuff method using a photoelectric sensor (IITC Life Science Instruments, Woodland Hills, CA) (35). A minimum of five pressures were recorded in each animal and averaged.

\section{ANGIOGRAPHIC METHODS}

To assess cardiac size and function, microangiography of the LV was performed $14 \mathrm{~d}$ after pump implantation, as described previously (36). Rats were anesthetized with ketamine/xylazine, placed in the supine position, intubated, and ventilated under positive pressure. Under a dissecting microscope, the right external jugular vein was cannulated with PE 50 tubing which was advanced into the superior vena cava. To facilitate ventriculographic analysis, heart rate was slowed in some animals from the resting anesthetized rate of about 300 beats $/ \mathrm{min}$ to 200 beats/min or less by intravenous administration of UL-FS $49(1,2,4,5$ tetrahydro-7,8-dimethoxy-3-[3-[\{2-(3,4-dimethoxyphenyl)ethyl\}methyl-imino] propyl]-2H-3-benzazepin-2-onhydrochloride) (zatebradine). UL-FS 49 is a specific bradycardic agent (sinus node inhibitor) which this laboratory has shown to have no direct negative inotropic effect $(37,38)$; mean doses were $0.125 \mathrm{mg}$ in the treated group (10 of 16 rats) and $0.067 \mathrm{mg}$ in the control group (6 of 12 rats).

During brief suspension of respiration, nonionic contrast medium (0.5 ml, Omnipaque 350; Sanafi-Winthrop Pharmaceuticals, New York) was injected into the superior vena cava over $2 \mathrm{~s}$ using a power injector (Cordis Laboratories Inc., Miami, FL). Angiograms were obtained under constant fluoroscopy (60 kVP and 1-2 mA), using a Fluoricon 300 (model MSI-1250 III; General Electric Co., Milwaukee, WI). The data were acquired in a 4.5 -in field of view and recorded on videotape using a standard interlaced scanning mode, with a 1-cm grid and lead marker placed at the level of the heart, as described elsewhere (36). Each animal was studied sequentially in $30^{\circ}$ right anterior oblique and $60^{\circ}$ left anterior oblique projections, using separate contrast injections.

Image acquisition and analysis. The details of the image processing and validation of analytic methods have been described (36). In brief $\mathrm{x}$-ray images were digitized at $30 \mathrm{frames} / \mathrm{s}$ with a resolution matrix of $512 \times 512$ pixels with 256 shades of gray using a time base corrector and Gould De Anza video processing system, which was interfaced to a VAX 11/750 computer system. Densitomographic analysis of a digitized loop was used to identify end-diastole and end-systole. Left ven- 
tricular end-diastolic volume (LVEDV) and end-systolic volume (LVESV) the stroke volume (SV), and the ejection fraction (EF) were calculated for two consecutive beats using the bi-plane area length method (39) and averaged.

In a previous study in rats, good agreement between directly determined and angiographically measured volumes was found (36); after diastolic cardiac arrest using $\mathrm{KCl}$, the mean volumes of balloons placed in the LV chamber, which were filled with variable known volumes of $\mathrm{x}$-ray contrast medium, were calculated by the area-length angiographic method and found to be $10 \mu 1$ higher than the actual mean volumes (upper and lower limits of agreement 90 and $-70 \mu \mathrm{l}, \pm 2$ SD) (36).

Evaluation of mitral regurgitation. To search for differences in mitral regurgitation between groups, a subset of eight rats (four control, four treated, not in the randomization groups) underwent echocardiographic and angiographic evaluation 2 wk after coronary occlusion. After anesthesia, the chest was shaved, and transthoracic ultrasonographic evaluation was performed with a 5-MHz transducer and a two-dimensional echo-color Doppler system (model 1000; Hewlett-Packard Co., Palo Alto, CA). Parasternal long axis and apical 2-chamber views were obtained with the rat in a supine position. Mitral regurgitation was identified on color pulsed wave Doppler by the presence or absence of a systolic jet in the left atrium. The right carotid artery was then cannulated, PE 50 tubing was advanced across the aortic valve into the left ventricle, and power injection of $0.2 \mathrm{~cm}^{3}$ of Omnipaque was performed in the oblique projections. Ventriculograms were digitized as described above and frame by frame advancement was used to assess the degree of mitral regurgitation.

We were unable to measure LV diastolic wall thickness reliably in vivo due to insufficient resolution of the echocardiographic system.

\section{IGF-1 LEVELS}

In a subset of 22 animals (control $n=11$, treatment $n=11$ ), IGF-1 levels were measured. Before killing, $1.5 \mathrm{~cm}^{3}$ of blood was collected in a heparinized syringe and centrifuged, and the plasma was obtained and stored at $-20^{\circ} \mathrm{C}$ before analysis. IGF-1 levels were measured by RIA at Genentech Laboratories. In brief, IGF-1 was separated from binding proteins by acid/ethanol precipitation. The RIA used rhIGF-1 as standard, the label was ${ }^{125}$ IGF-1, and a polyclonal rabbit antibody to IGF-1, which measures both riGF-1 and endogenous rat IGF-1, was added to measure total serum IGF-1 (40).

\section{POSTMORTEM AND HISTOLOGIC STUDIES}

After angiography, rats were killed and the hearts were fixed $(34,36)$. In brief, the heart was arrested with $\mathrm{KCl}$ solution, and polyethylene catheters were introduced into the LV apex and the descending aorta. The LV cavity was then filled and maintained at $10 \mathrm{mmHg}$. After washout of blood from the coronary arteries with heparinized saline $(10,000 \mathrm{U} /$ liter $)$ for $3 \mathrm{~min}$, the myocardium was perfused retrogradely from the aorta with $1 \%$ glutaraldehyde, $2 \%$ paraformaldehyde solution at a constant pressure of $60 \mathrm{mmHg}$ for $10 \mathrm{~min}$. The right atrium and pulmonary artery were opened to decompress the right ventricle during fixation.

After hardening, the heart was excised and immersed in the $1 \%$ glutaraldehyde, $2 \%$ paraformaldehyde solution for $24 \mathrm{~h}$. Subsequently, the atria and adhesions were dissected away and the right and left ventricles were separated and weighed, the interventricular septum being included with the LV. To compare heart weights among groups, heart weights were normalized by the length of the tibia as well as by the body weight. The right tibia was dissected, and its length from the condyles to the tip of the medial malleolus was measured with a micrometer caliper by the method of Yin et al. (41).

Myocardial infarct size. After $48 \mathrm{~h}$ in the buffered solution, the whole LV was divided into thirds along its long axis. The apical and middle thirds were embedded in paraffin, and a portion of the septal region of the basal third was embedded in epoxy. Serial transverse sections $10-\mu \mathrm{m}$-thick were cut, and every 100 th section from the apex to base (1 mm apart) was mounted and stained with Milligan's trichrome. Slides taken at the fifth and sixth millimeter from the apex were analyzed blindly for infarct size $(34,36)$; on each slide, the percent infarct size was estimated from the ratio of the infarct area to the total area of the LV slice, assessed by computerized planimetry expressed as a percentage of the total slice area, and averaged for the two sections. This approach was previously shown to correlate well with total infarct size calculated using all serial sections (34).

Collagen content. Serial transverse sections $10-\mu \mathrm{m}$-thick adjacent to those stained with trichrome were taken at the site of the fourth, fifth, and sixth slices from the apex, mounted, and stained with picrosirius red $(0.1 \% \mathrm{wt} / \mathrm{vol}$ sirius red F3BA; Roboz Surgical Instruments Co., Inc., Rockville, MD), as previously described (42). Image analysis was performed by the semiautomated method of MacKenna (43) using a Sony (CMA-D1) RGB color camera mounted on a computer-interfaced Nikon light microscope. Sections of the septum (distant from the infarct) were magnified $\times 40$ and 8-9 fields per slice were examined, yielding 25 fields per heart for obtaining the collagen area fraction. Under polarized light microscopy, the sample was rotated on a circular stage until the autobirefringence of the muscle and extracellular space were extinct, to ensure that only the collagen was birefringent. The images were then transformed into an 8-bit gray scale brightness channel and thresholded into a binary black and white image to yield a consistent level of background noise ( $0.5-0.9 \%$ of total pixels) in separating tissue from extracellular space. The following calculation was then made:

Area fraction of collagen

$=\frac{\text { pixels of birefringent collagen }- \text { background }}{\text { pixels of tissue. }}$

Area fraction of collagen is the area occupied by collagen per slice (a measure of the concentration of interstitial fibrillar collagen). This technique has been shown to have excellent correlation with hydroxyproline analysis of collagen content (44).

Cell size. Tissue blocks obtained from the basal third of the septum were embedded in epoxy and oriented so that the midwall muscle fibers would be cut transversely. The slices were then mounted and fixed with toluidine blue. Adequate orientation of the midwall of each section was confirmed by evaluating the circularity of the midwall muscle fibers and capillaries. The slides were then magnified $\times 40$, and the image was captured by a Hitachi KP-140 BW video camera, digitized, and analyzed using the Image 1.40 program. After identifying the midwall, all myocytes with a well defined cellular membrane and visible nucleus were measured. A minimum of 250 cells from 3 blocks was counted and averaged to yield an average myocyte cross-sectional area.

Capillary density. Using a previously described method (45), in a subset of 14 animals ( 7 control, 7 treated) the capillaries were dilated with adenosine $(2 \mathrm{mg} / \mathrm{liter})$ added to the heparinized saline perfusate, followed by fixation; the vasodilator was used to assure maximum arteriolar dilation and perfusion of all capillaries (45). Tissue blocks from the basal septum (noninfarcted tissue) were oriented to cut the midwall fibers transversely and then sliced in $1-\mu \mathrm{m}$-thick sections. The slices were mounted and stained with toluidine blue. The slides were then magnified $\times 40$ and analyzed using the same equipment and programs used for cell size measurements. Vessels $<2 \mu \mathrm{m}$ and $>8 \mu \mathrm{m}$ in diameter and elliptical vessels with a major to minor axis ratio $<0.7$ were excluded. All capillaries within a given area were counted and the number of capillary cross sections per square millimeter was recorded. A minimum of 10 fields was counted from 3 blocks and the results were averaged.

\section{STATISTICAL METHODS}

Comparisons between IGF-1-treated and control groups for all variables at $14 \mathrm{~d}$ were made using Student's $t$ tests (two-tailed). In addition, for some analyses, based on the median infarct size of all treated and control animals of $25.86 \%$, rats were assigned either to a small or a large infarct group; analysis of variance with treatment and infarct size groupings was performed, with significant interactions adjusted for multiple comparisons by a Bonferroni test. 
Table I. Dose Response of IGF-1 in Noninfarcted Rats

\begin{tabular}{|c|c|c|c|c|}
\hline Group & $\begin{array}{l}\text { Control group } \\
\quad \text { (placebo } \\
\times 14 \mathrm{~d})\end{array}$ & $\begin{array}{l}\text { Low dose } \\
(1 \mathrm{mg} / \mathrm{kg} \text { per } \mathrm{d} \\
\times 14 \mathrm{~d})\end{array}$ & $\begin{array}{c}\text { Medium dose } \\
(2.2 \mathrm{mg} / \mathrm{kg} \text { per d } \\
\times 25 \mathrm{~d})\end{array}$ & $\begin{array}{c}\text { High dose } \\
(3 \mathrm{mg} / \mathrm{kg} \text { per d } \\
\times 14 \mathrm{~d})\end{array}$ \\
\hline BW $(g)$ & $257.1 \pm 12.4$ & $267.4 \pm 7.4$ & $289.3 \pm 18.8 *$ & $288.7 \pm 12.7 *$ \\
\hline $\mathrm{TL}(\mathrm{mm})$ & $37.87 \pm 1.4$ & $39.22 \pm 1.07$ & $39.08 \pm 0.99^{\ddagger}$ & $39.93 \pm 0.35^{*}$ \\
\hline \multicolumn{5}{|l|}{ LV weight } \\
\hline$(g)$ & $0.66 \pm 0.06$ & $0.69 \pm 0.03$ & $0.84 \pm 0.11^{*}$ & $0.88 \pm 0.08 *$ \\
\hline LV/BW & $0.26 \pm 0.03$ & $0.26 \pm 0.01$ & $0.29 \pm 0.03$ & $0.30 \pm 0.02^{\ddagger}$ \\
\hline LV/TL & $1.75 \pm 0.17$ & $1.78 \pm 0.1$ & $2.14 \pm 0.23 *$ & $2.20 \pm 0.19 *$ \\
\hline \multicolumn{5}{|l|}{ RV weight } \\
\hline$(g)$ & $0.16 \pm 0.02$ & $0.14 \pm 0.03$ & $0.17 \pm 0.03$ & $0.21 \pm 0.03^{\ddagger}$ \\
\hline $\mathrm{RV} / \mathrm{BW}$ & $0.06 \pm 0.01$ & $0.05 \pm 0.01$ & $0.06 \pm 0.01$ & $0.07 \pm 0.01$ \\
\hline $\mathrm{RV} / \mathrm{TL}$ & $0.43 \pm 0.06$ & $0.37 \pm 0.09$ & $0.43 \pm 0.07$ & $0.54 \pm 0.07^{\ddagger}$ \\
\hline
\end{tabular}

$B W$, body weight; $T L$, tibial length; $R V$, right ventricular. Mean values \pm SD, ${ }^{\ddagger} P<0.05, * P<0.01$.

\section{Results}

\section{IGF-1 administration in normal rats}

The effects of incremental doses of IGF-1 in normal rats without myocardial infarction are shown in Table I. Due to the concomitant increase in body weight, when LV weight was normalized to body weight a significant increase in LV weight to body weight ratio was seen only in the high dose group (18\%, $P$ $<0.05)$. When normalized to the tibial length, a greater increase in LV weight compared with control was seen in both the medium and high dose groups ( 22 and $26 \%$, respectively, $P<0.01$ ). Additionally, there was a significant increase in the right ventricular weight to tibial length ratio in the high dose group (25\%, Table I).

Thus, significant cardiac hypertrophy could be induced by IGF-1 in vivo in the normal rat, and, based on the finding that the high dose administered for a shorter time and at lower total dose was at least as effective as the medium dose, $3 \mathrm{mg} / \mathrm{kg}$ per $\mathrm{d}$ for $14 \mathrm{~d}$ was given in the subsequent randomized trial.

Trial of IGF-1 administration in rats with myocardial infarction

Of the $\mathbf{4 0}$ rats randomized to the experimental protocol (20 control, 20 treated), 5 animals died ( 4 control, 1 treated) during the course of therapy, and 3 animals ( 2 control, 1 treated) did not have a transmural infarction postmortem. Four animals (two control, two treated) died during angiography. Therefore, 28 animals ( 12 control, 16 treated ) were available for the analysis.

Plasma levels of IGF-1 obtained before killing showed in the control group values ranging from 53.1 to 359.1 (mean $228.9 \pm 87.2 \mathrm{ng} / \mathrm{ml}$ ). Values in the treated animals ranged from 106.2 to $1,011.6 \mathrm{ng} / \mathrm{ml}$ (mean $600.8 \pm 260 \mathrm{ng} / \mathrm{ml}, P<0.004$ compared with controls). IGF-1 levels were undetectable in two of the treated animals; the complete lack of radioactive signal in the sample suggests a technical problem in the measurement and not absence of IGF-1. However, if the serum levels are assumed to be $0 \mathrm{ng} / \mathrm{ml}$ in these two animals, the mean value of $491.6 \mathrm{ng} / \mathrm{ml}$ in the treated group remains significantly elevated compared with the control group $(P<0.03)$.

Systemic arterial pressures and heart rates. The systemic arterial pressure and heart rate were measured $9 \mathrm{~d}$ after random-
Table II. Heart and Organ Weights after Myocardial Infarction

\begin{tabular}{lccc}
\hline & $\begin{array}{c}\text { Control } \\
(n=12)\end{array}$ & $\begin{array}{c}\text { Treated } \\
(n=16) \text { IGF- }\end{array}$ & $P$ value \\
\hline BW $(g)$ & $237.5 \pm 18.4$ & $276.8 \pm 18.4$ & $<0.0001$ \\
LV weight $(g)$ & $0.63 \pm 0.08$ & $0.71 \pm 0.07$ & 0.005 \\
LV/BW & $0.26 \pm 0.04$ & $0.26 \pm 0.02$ & NS \\
LV/TL & $1.62 \pm 0.2$ & $1.83 \pm 0.2$ & $<0.05$ \\
RV weight $(g)$ & $0.19 \pm 0.05$ & $0.22 \pm 0.05$ & NS \\
Liver $(g)$ & $8.6 \pm 1.2$ & $9.9 \pm 1.3$ & 0.001 \\
Kidney $(g)$ & $2.0 \pm 0.3$ & $2.7 \pm 0.2$ & $<0.00001$ \\
Spleen $(g)$ & $0.9 \pm 0.1$ & $1.6 \pm 0.4$ & $<0.00001$ \\
& & & \\
\hline
\end{tabular}

Treated $=$ IGF-1 at a dose of $3 \mathrm{mg} / \mathrm{kg}$ per $\mathrm{d}$ for $2 \mathrm{wk}$, values \pm SD. $P$ values, two-tailed. $T L$, tibial length in millimeters; $B W$, body weight.

ization using a tail cuff monitor in a subgroup of 10 control and 8 treated conscious animals. A small rise in systolic blood pressure was seen in the treated group compared with the control group, (116 \pm 14 [SD] vs $103 \pm 12 \mathrm{mmHg}$, respectively, $P$ $=0.05$ ). There was no significant difference in the heart rates between the treated group compared with the controls ( 422 vs 404 beats $/ \mathrm{min}$ ).

Effects of IGF-1 on body, organ, and heart weights (Table II, Fig. 1). Ventricular weights, absolute and normalized to body weight and tibial length, are summarized in Table II. IGF-1 administration induced an increase in body weight averaging $17 \%$ and disproportionately increased kidney and spleen weights. Tibial length increased significantly by $3.6 \%$ (Table II).

In rats with myocardial infarction, there was a significant increase in LV weight in the IGF-1 -treated group, which was not significant when normalized to body weight (Table II). When normalized to the tibial length, there was a significant increase in the LV weight in the treated animals (Fig. 1). The small increase in right ventricular weight in the treated group was not statistically significant.

$L V$ volumes and function in vivo (Table III). In untreated rats with myocardial infarction, compared with normal rats the mean LVEDV was increased and marked LV dysfunction was indicated by an average LVEF of $32.8 \%$ (EF $70 \%$ in normal rats [34]). In the IGF-1 treatment group, there was a significant increase in LVEDV of $19 \%$ compared with untreated rats $(0.69$ vs $0.58 \mathrm{ml}$ ) (Fig. 2). This increase was not significant when normalized to body weight but was significant when normalized to tibial length (Fig. 2).

The increased LVEDV in the treated group, without significant change in the LVESV, yielded a highly significant (32\%) increase in the SV (Fig. 3). Since the mean heart rates under anesthesia at angiography were identical (176 beats/min) in treated and control groups, there was a $32 \%$ increase in estimated angiographic cardiac output. When the SV was normalized to body weight, there was no significant difference between groups (Table III), although when normalized to the tibial length, the increase in SV was significant (Fig. 3).

The LVEF in treated animals was not significantly different compared with controls ( 34.9 vs $32.8 \%$, respectively). However, when animals were subdivided into groups with small and large myocardial infarctions based on the median infarct size, analysis of variance showed a significant interaction ( $P$ $=0.029$ ) for EF between infarct size group and treatment. The 


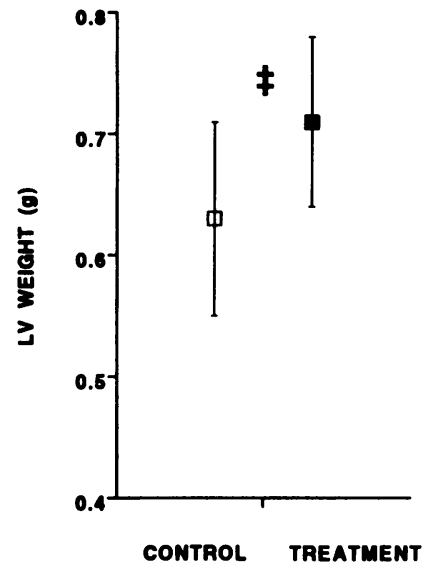

CONTROL TREATMENT

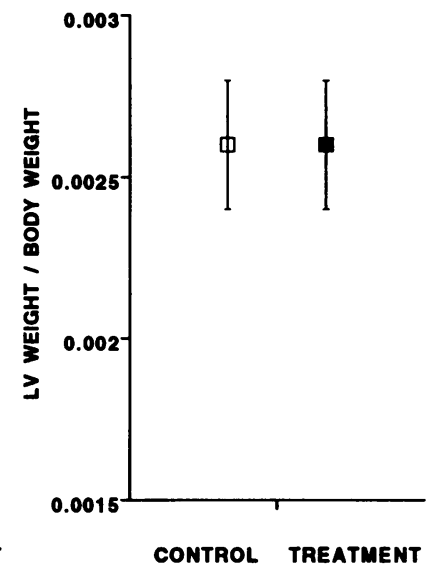

CONTROL TREATMENT

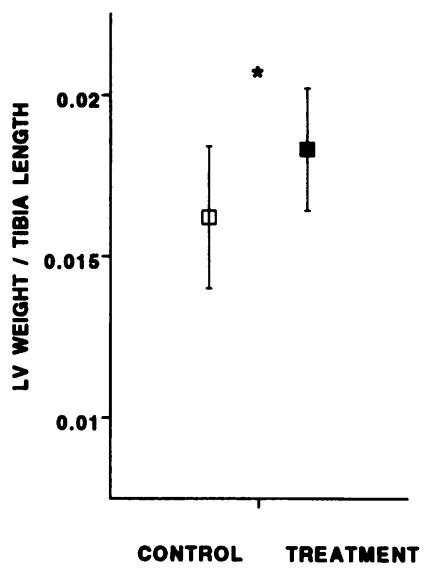

Figure 1. LV weight: absolute weight (left) and normalized for body weight (middle) and tibial length (right). Control group, open squares; and treated group, closed squares. Bars indicate $\pm \mathrm{SD},{ }^{*} P<0.05,{ }^{\ddagger} P<0.01$. apparent sizable increase of the LVEF in the IGF-1-treated group with large infarctions compared with the control group ( 33.4 vs $25.0 \%$, respectively) without an appreciable difference in groups with small infarctions (Fig. 4) was of borderline significance by the post-hoc Bonferroni test.

Whether or not IGF-1 administration could have caused or enhanced mitral regurgitation was assessed in subsets of rats using angiography and echocardiography. Color echocardiographic studies showed a trace of mitral regurgitation in one of the four control animals and in none of four treated animals, whereas Doppler signals demonstrated no regurgitation in control or treated animals. Direct injection of contrast medium into the left ventricle failed to detect angiographic evidence of mitral regurgitation in any of the eight rats studied.

\section{Postmortem studies}

Effects of IGF-1 on myocardial infarct size. The mean infarct areas in the treated and untreated groups were similar, and the size of the infarction expressed as a percentage of the total LV slice area also was not different (Table IV). In addition, the range of infarct sizes was similar between the two groups. Therefore the differences in LVEDV and SV seen in the IGF1 -treated animals could not be related to a difference in infarct size.

Effects of IGF-1 on collagen content, cell size, and capillary density. IGF-1 treatment was associated with no significant difference compared with controls in the area fraction of collagen,

Table III. Ventricular Volumes (Milliliters $\pm S D$ ) after Myocardial Infarction

\begin{tabular}{lllr}
\hline & $\begin{array}{c}\text { Control } \\
(n=12)\end{array}$ & $\begin{array}{c}\text { Treated } \\
(n=16) \text { IGF-1 }\end{array}$ & $P$ value \\
\hline LVEDV $(m l)$ & $0.58 \pm 0.12$ & $0.69 \pm 0.09$ & 0.007 \\
LVESV $(m l)$ & $0.40 \pm 0.12$ & $0.45 \pm 0.07$ & NS \\
SV $(m l)$ & $0.18 \pm 0.05$ & $0.24 \pm 0.06$ & 0.01 \\
EF $(\%)$ & $32.8 \pm 10$ & $34.9 \pm 7.5$ & NS \\
LVEDV/BW $(m / g)$ & $0.25 \pm 0.06$ & $0.25 \pm 0.04$ & NS \\
LVEDV/TL & $1.51 \pm 0.33$ & $1.79 \pm 0.23$ & 0.01 \\
SV/BW & $0.08 \pm 0.02$ & $0.09 \pm 0.02$ & NS \\
SV/TL & $0.48 \pm 0.01$ & $0.63 \pm 0.02$ & 0.01 \\
& & & \\
\hline
\end{tabular}

$B W$, body weight; $T L$, tibial length. a measure of the concentration of interstitial fibrillar collagen (Table IV).

Myocyte cross-sectional areas were not significantly different between groups, although there was a trend toward larger cross-sectional areas in IGF-1 - treated rats compared with controls (232.1 vs $205.4 \mu \mathrm{m}^{2}$, respectively, $P=0.10$ ).

There was no significant difference in the capillary density between the control and treated groups (Table IV).

Together, these findings suggest that IGF-1 did not induce a pathologic form of hypertrophy associated with increased fibrosis and reduced capillary density.

\section{Discussion}

Using an in vitro cultured myocardial cell model system, a number of hormonal and peptide-derived growth factors have been shown to activate defined features of the hypertrophic response, including an increase in cell size, organization of contractile proteins into sarcomeric units, and in the induction of an embryonic gene program (46). Also, upregulation of the expression of the ANF gene, a well accepted genetic marker for the hypertrophic phenotype, can be produced by endothelin1 (17), angiotensin II (47), TGF $\beta$ (13), and fibroblast growth factor (13). IGF-1, but not GH, also can activate a hypertrophic response in this neonatal cultured cell system (22), and IGF-1 produces a direct anabolic effect on cultured adult rat myocardial cells (23). Since IGF-1 mediates many of the effects of GH on target tissues, experimental studies documenting that excessive GH can lead to cardiac enlargement (48) raise the possibility that IGF-1 might have a direct effect on cardiac muscle cell growth in the in vivo setting. Moreover, the upregulated expression of IGF-1 in the LV during the development of experimental cardiac hypertrophy $(24,25)$ suggests that it may be a candidate gene for activating defined features of the hypertrophic response, as mentioned earlier. However, there has been little direct evidence indicating that IGF-1 or any of the other known peptide-derived growth factors which activate the appearance of the hypertrophic phenotype in vitro is capable of activating hypertrophy in vivo.

IGF-1 activates cardiac muscle hypertrophy in vivo. This study was designed to assess the in vivo effects of IGF-1 administration on cardiac hypertrophy and to determine whether or not such hypertrophy is beneficial or detrimental when induced in the setting of impaired cardiac function during the recovery 

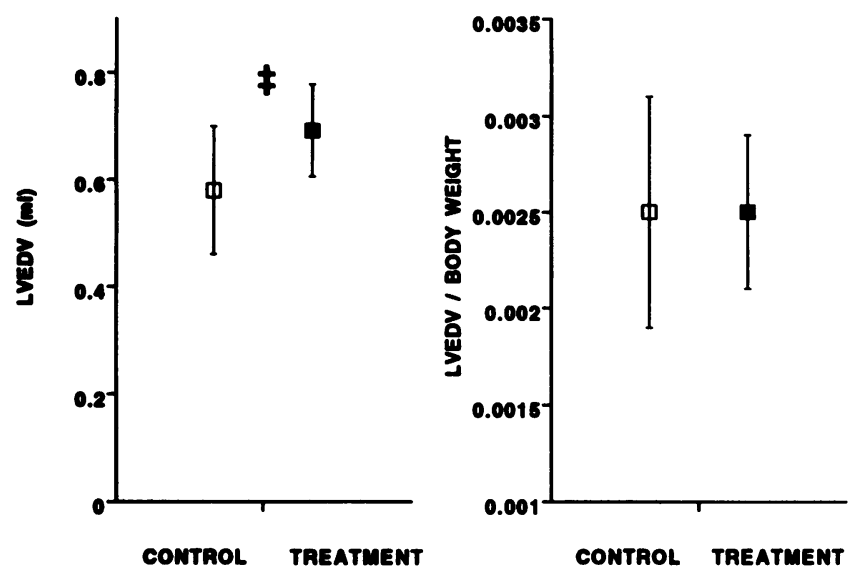

period after myocardial infarction. Absolute LV weight increased considerably with IGF-1 treatment both in normal rats and in the rats with myocardial infarction. The LV/body weight ratio increased significantly in normal rats treated with $3 \mathrm{mg} /$ $\mathrm{kg}$ per $\mathrm{d}$ of IGF-1, but this ratio remained unchanged in IGF1 -treated rats with infarction, although a significant increase occurred in the absolute LV weight and the LV weight/tibial length ratio. In normal rats, the tibial length changes minimally beyond maturity, remains independent of changes in body weight, and correlates better than body weight with changes in cardiac cell size during aging (41). In several types of catabolic states in rats, IGF-1 has been shown to increase body weight and to augment the fractional weights (grams per kilogram of body weight) of the stomach and gut, kidneys, spleen, and thymus (49). Fractional weights of the eviscerated carcass (primarily muscle and bone), heart, skin, liver, and lungs were not altered by IGF-1 administration; moreover, carcass fat content was not increased by IGF-1 and there was no change in carcass nitrogen content per gram, indicating that IGF-1 stimulated growth in lean tissue (49). Because of the disproportionate growth of some organs and the possibility of edema formation in our study, heart weights were normalized by tibial length, as well as body weight, since tibial length has been proposed as a better measure of the amount of lean body tissue than the total body weight (41). Had the lean carcass weight (fat extracted) been measured in our experiments, it is uncertain whether the ratio of heart weight to lean carcass weight would have been altered by IGF-1 administration.

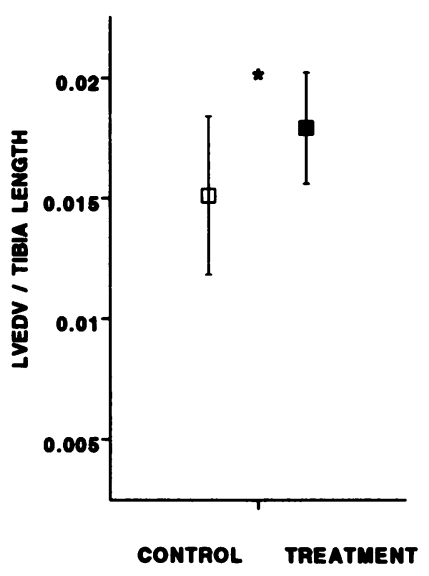

Figure 2. LVEDV: absolute volume (left) and normalized for body weight (middle) and tibial length (right). Other symbols as in Fig. 1.

Myocardial infarction in rats is known to stimulate compensatory hypertrophy of the noninfarcted myocardium, characterized by some increase in myocyte diameter but a greater increase in myocyte length $(48,49)$. Previous studies with excess GH in normal rats have shown an increase in cell length with little or no change in cross-sectional area (28). Compared to the control animals with infarction, IGF-1 treatment in our experiments produced only a trend for myocyte cross-sectional area to increase, but the fixation technique used in this study to determine myocardial infarct size is a limitation of our study; this approach did not permit examination of changes in myocyte length by electron microscopy (50) or study of isolated myocytes (51), which have shown dominant cell length changes in this setting of eccentric hypertrophy after myocardial infarction $(50,51)$.

The present findings in the postinfarction model, together with observations in the normal rat, provide the first evidence that an administered peptide-derived growth factor is associated with activation of a hypertrophic response in vivo. The minimal effects of IGF-1 on heart rate and systemic arterial blood pressure level support a possible direct effect of IGF-1 on cardiac hypertrophy in the myocardial infarction model. A component of the cardiac hypertrophy could have been in response to the increases in body and organ weights produced by IGF-1, which also could have contributed to an increase in the output of the failing heart. However, compensatory hypertrophy alone in the control group was inadequate to prevent the marked decrease in cardiac function, despite the stimulus of cardiac overload

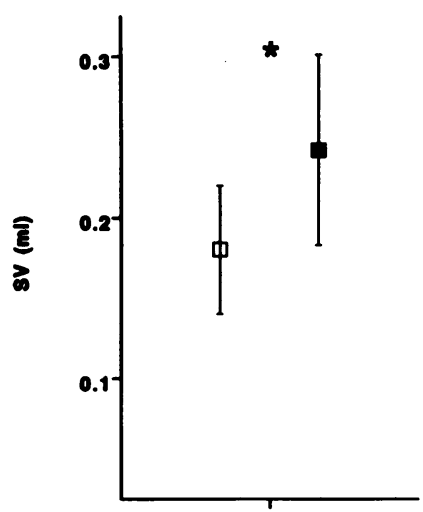

CONTAOL TAEATMENT

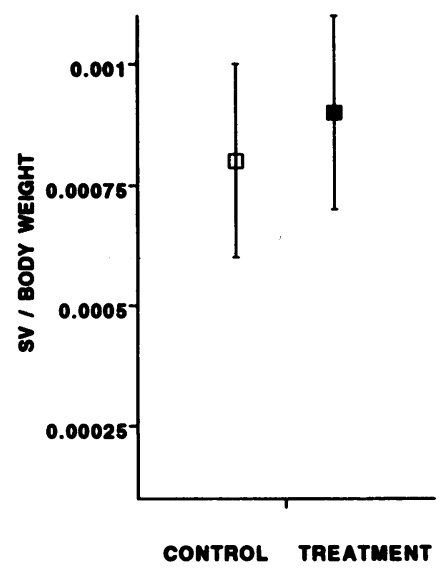

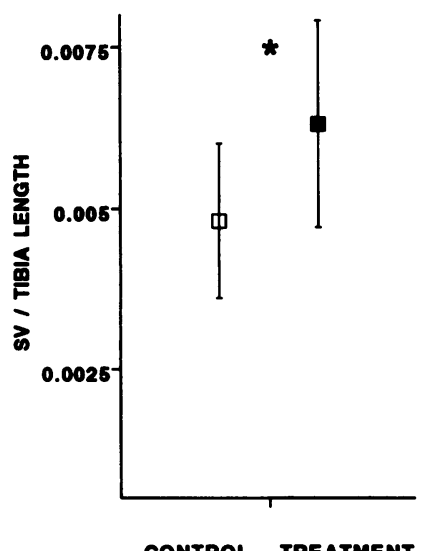

CONTROL TREATMENT
Figure 3. SV: absolute volume (left) and normalized for body weight (middle) and tibial length (right). Other symbols as in Fig. 1. 


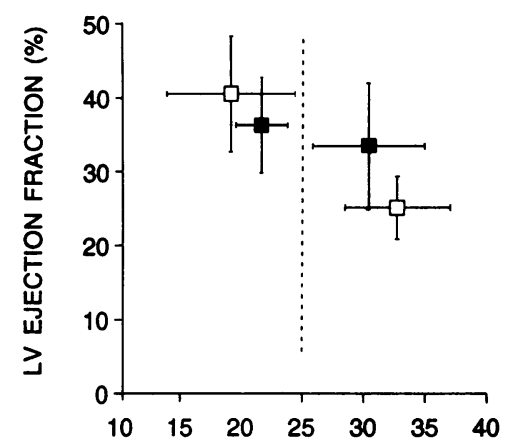

MYOCARDIAL INFARCTION (\% LV)
Figure 4. LVEF in control groups (open squares) and treated groups (closed squares) divided according to the median infarct size of all animals $(25.9 \%$, dashed vertical line). Infarct size is expressed as a percentage of LV myocardial area. In each category of infarct size, $n$ $=6$ for control and $n=$ 8 for treated animals. There was a significant interaction by ANOVA for infarct size between treated and control groups $(P=0.029)$, which was of borderline statistical significance only in the large infarct size group by post-hoc testing. There were no significant differences in infarct size between treated and control animals in the two categories of infarct size.

secondary to the infarction. The pericardium was opened at operation in both groups of animals which might have resulted in increased acute cardiac dilation, but the effect of this procedure, if any, on cardiac enlargement at 2 wk is uncertain. Overall, the present experiments appear to demonstrate the capability of the overloaded and depressed heart to undergo additional enlargement and hypertrophy as a consequence of an exogenously administered growth factor.

IGF-1-mediated hypertrophy, ventricular remodeling, and performance in dysfunctional hearts. The association of IGF-1 administration in vivo with a physiologic hypertrophic response in the normal rats suggested its potential value as a therapeutic agent to alter remodeling after myocardial infarction and thereby to potentially improve global cardiac function in the setting of heart failure. In previous experiments, rats with doxorubicin-induced cardiomyopathy showed no significant increase in heart weight after IGF-1 infusion $(0.8 \mathrm{mg} / \mathrm{kg}$ per $\mathrm{d}$ for 3 wk), although body weight increased transiently and the cardiac index was higher in treated compared with untreated animals (52). The present study using a well characterized experimental model of cardiac failure after myocardial infarction in the rat (7) provides evidence that relatively short-term administration of IGF-1 does not appear to be detrimental and may improve cardiac performance while increasing cardiac size during the development of this form of experimental cardiac failure. However, the effect of IGF-1 to increase diastolic volume in this study also could be interpreted as an unfavorable event. This apparent contradiction will require further investigation, since angiotensin converting enzyme inhibitors have shown beneficial effects after acute myocardial infarction in the clinical setting (5), as well as after experimental myocardial infarction in which these agents reduce excessive LV dilation and inhibit hypertrophy (7).

Prior studies on hypertrophy after myocardial infarction in the rat have included assessment of thyroid hormone, which caused an increase in heart weight and $L V \mathrm{dp} / \mathrm{dt}_{\max }$ with decreased LV end-diastolic pressure in treated compared with control rats (53), although the positive inotropic effects of the hormone rather than hypertrophy per se may have been dominant. A marked hypertrophic effect on noninfarcted myocardium of an inhibitor of fatty acid metabolism has been reported,
Table IV. Postmortem Studies

\begin{tabular}{|c|c|c|c|}
\hline & Control & Treated & $P$ value \\
\hline Infarction (\% LV area) & $\begin{array}{l}25.9 \pm 8.5 \\
(n=12)\end{array}$ & $\begin{array}{l}26.0 \pm 5.7 \\
(n=16)\end{array}$ & NS \\
\hline Scar area $\left(\mathrm{mm}^{2}\right)$ & $\begin{array}{r}6.5 \pm 3.1 \\
(n=12)\end{array}$ & $\begin{array}{c}6.0 \pm 1.6 \\
(n=16)\end{array}$ & NS \\
\hline $\begin{array}{l}\text { Collagen area fraction } \\
(\%)\end{array}$ & $\begin{array}{l}2.8 \pm 1.0 \\
(n=8)\end{array}$ & $\begin{array}{l}2.3 \pm 0.9 \\
(n=8)\end{array}$ & NS \\
\hline $\begin{array}{l}\text { Capillary density } \\
\left.\text { (profiles } / \mathrm{mm}^{2}\right)\end{array}$ & $\begin{array}{c}3607 \pm 297 \\
(n=7)\end{array}$ & $\begin{array}{l}3720 \pm 327 \\
(n=7)\end{array}$ & NS \\
\hline $\begin{array}{l}\text { Myocyte cross-sectional } \\
\text { area }\left(\mu m^{2}\right)\end{array}$ & $\begin{array}{c}205.4 \pm 23.2 \\
\quad(n=9)\end{array}$ & $\begin{array}{c}232.1 \pm 40.2 \\
(n=10)\end{array}$ & 0.1 \\
\hline
\end{tabular}

Values are mean $\pm \mathrm{SD}$.

accompanied by amelioration of unfavorable LV remodeling, which was associated with fatty acid infiltration of the myocardium (54).

Nature of the hypertrophic response associated with IGF1. The increase in myocardial weight induced by IGF-1 appears to be due mainly to myocyte hypertrophy without an increase in extracellular matrix. Whereas both groups showed somewhat increased collagen levels compared with normal (55), there was no difference statistically between the groups with only a trend toward less collagen in the IGF-1-treated group. Given the ubiquitous role of IGF-1 in enhancing growth, it is of interest that it caused no apparent induction of collagen synthesis in this animal model.

The finding of unchanged capillary density in the IGF-1treated group suggests the possibility that, despite a larger LV weight, IGF-1 might stimulate appropriate growth of capillaries in this setting. We measured capillary density, rather than capillary/myocyte ratio. Capillary density has been shown to be mildly reduced in one form of overload hypertrophy (aortic regurgitation) (56); on the other hand, the capillary/myocyte ratio was reported to be unchanged in rats $40 \mathrm{~d}$ after myocardial infarction, although concomitant electron microscopic studies allowed calculations which showed reduced capillary lumenal surface area relative to the volume of myocytes (50). Since neither the myocyte cross-sectional area nor capillary density was significantly altered in the present experiments, a significant change in the capillary/myocyte ratio between groups seems very unlikely. It is possible, however, that subtle differences might have been detected had electron microscopy been performed. Together, the findings on capillary density and lack of increased fibrosis may characterize a physiologic form of hypertrophy induced by IGF-1.

This study suggests that the activation of a physiological form of hypertrophy may be beneficial in the setting of heart failure during recovery from acute myocardial infarction and that growth factor therapy might represent a new and rational therapeutic approach for treating some forms of cardiac failure. Whether or not this approach would be useful in the presence of generalized systolic or diastolic myocardial dysfunction remains to be determined. It should be recognized that this study concerned the short-term use of relatively large doses of IGF1 in an evolving myocardial infarction model of LV dysfunction, and longer term studies are planned. Also, IGF-1 stimulated substantial growth of several organs and body weight in 
this study. Since IGF-1 is a pleiotropic growth factor, the isolation and characterization of growth factors with relatively restricted cardiac selectivity could be advantageous. On the other hand, since weight loss is often a significant problem in severe clinical heart failure, trophic effects of IGF-1 on lean body mass might be beneficial in that setting. Based on these initial observations, additional experiments seem warranted to further evaluate the potential therapeutic role of IGF-1 and other novel and/or known growth factors which might be capable of activating physiological forms of cardiac hypertrophy in the failing heart.

\section{Acknowledgments}

The authors are grateful to Elizabeth Gilpin for statistical analyses. We also thank Denice Jio-Brannigan and Farid Abdel-Wahhab for excellent technical assistance and Cheryl Bugsch for expert manuscript preparation.

This work was supported in part by a Coronary Heart Disease SCOR grant HL-17682 awarded by the National Heart, Lung and Blood Institute. Dr. Duerr was supported by an American Heart Association-Bugher Foundation Fellowship.

\section{References}

1. Schaper, J., and W. Schaper. 1983. Ultrastructural correlates of reduced cardiac function in human heart disease. Eur. Heart J. 4(Suppl. A):35-42.

2. Ross, J., Jr. 1976. Afterload mismatch and preload reserve: a conceptua framework for the analysis of ventricular function. Prog. Cardiovasc. Dis. 18:225-264.

3. Gerdes, A. M., S. E. Kellerman, J. A. Moore, K. E. Muffly, L. C. Clark P. Y. Reaves, K. B. Malec, P. P. McKeown, and D. D. Schocken. 1992. Structura remodeling of cardiac myocytes in patients with ischemic cardiomyopathy. Circulation. 86:426-430.

4. Olivetti, G., J. M. Capasso, L. G. Meggs, E. H. Sonnenblick, and P. Anversa 1991. Cellular basis of chronic ventricular remodeling after myocardial infarction in rats. Circ. Res. 68:856-869.

5. Pfeffer, M. A., E. Braunwald, L. A. Moye, L. Basta, E. J. Brown, Jr. T. E. Cuddy, B. R. David, E. M. Geltman, S. Goldman, G. C. Flaker, et al. 1992 Effect of captopril on mortality and morbidity in patients with left ventricular dysfunction after myocardial infarction. Results of the survival and ventricular enlargement trial. The SAVE Investigators. N. Engl. J. Med. 327:669-677.

6. Baker, K. M., M. I. Chernin, S. K. Wixson, and J. F. Aceto. 1990. Reninangiotensin system involvement in pressure-overload cardiac hypertrophy in rats. Am. J. Physiol. 259 (Heart Circ. Physiol. 28):H324-H332.

7. Pfeffer, J. M., M. A. Pfeffer, and E. Brauwald. 1985. Influence of chronic captopril therapy on the infarcted left ventricle of the rat. Circ. Res. 57:84-95.

8. Rockman, H. A., S. P. Wachhorst, and J. Ross, Jr. 1994. Angiotensin II receptor blockade prevents ventricular hypertrophy and ANF gene expression with pressure overload in mice. Am. J. Physiol. 266:H2468-H2475.

9. Chien, K. R. 1993. Molecular advances in cardiovascular biology. Science (Wash. DC). 260:916-917.

10. Chien, K. R., K. U. Knowlton, H. Zhu, and S. Chien. 1991. Regulation of cardiac gene expression during myocardial growth and hypertrophy: molecular studies of adaptive physiologic response (review). FASEB (Fed. Am. Soc. Exp. Biol.) J. 5:3037-3046.

11. Knowlton, K. U., E. Baracchini, R. S. Ross, A. N. Harris, S. A. Henderson, S. M. Evans, C. Glembotski, and K. R. Chien. 1991. Co-regulation of the atria natriuretic factor and cardiac myosin light chain-2 genes during $\alpha$-adrenergic stimulation of neonatal rat ventricular cells. J. Biol. Chem. 266:7759-7768.

12. Knowlton, K. U., M. C. Michel, M. Itani, H. E. Shubeita, K. Ishihara, J. H. Brown, and K. R. Chien. 1993. The $\alpha_{1 \mathrm{~A}}$-adrenergic receptor subtype mediates biochemical, molecular, and morphologic features of myocardial cell hypertrophy. J. Biol. Chem. 268:15374-15380.

13. Parker, T. G., S. E. Packer, and M. D. Schneider. 1990. Peptide growth factors can provoke fetal contractile protein gene expression in rat cardiac myocytes. J. Clin. Invest. 85:507-514.

14. Long, C. S., C. J. Henrich, and P. C. Simpson. 1991. A growth factor for cardiac myocytes is produced by cardiac nonmyocytes. Cell Regul. 2:1081-1095.

15. Rockman, H. A., S. Ono, R. S. Ross, L. R. Jones, M. Karimi, V. Bhargava J. Ross, Jr., and K. R. Chien. 1994. Molecular and physiological alterations in murine ventricular dysfunction. Proc. Natl. Acad. Sci. USA. 91:2694-2698.

16. Shubeita, H. E., P. M. McDonough, A. Harris, K. U. Knowlton, C. Glem- botski, J. H. Brown, and K. R. Chien. 1990. Endothelin induction of sarcomere assembly and cardiac gene expression in ventricular myocytes: a paracrine mechanism for myocardial cell hypertrophy. J. Biol. Chem. 265:20555-20562.

17. Schneider, M. D., and T. G. Parker. 1990. Cardiac myocytes as targets for the action of peptide growth factors. Circulation. 81:1443-1456.

18. Rinderknecht, E., and R. E. Humbel. 1978. The amino acid sequence of human insulin-like growth factor I and its structural homology with proinsulin. J. Biol. Chem. 253:2769-2776.

19. Mathews, L. S., G. Norstedt, and R. D. Palmiter. 1986. Regulation of insulin-like growth factor I gene expression by growth hormone. Proc. Natl. Acad. Sci. USA. 83:9343-9347.

20. Murphy, L. J., G. I. Bell, M. L. Duckworth, and H. G. Friesen. 1987. Identification, characterization and regulation of a rat complementary deoxyribonucleic acid which encodes insulin-like growth factor I. Endocrinology. 121:684 691.

21. Isgaard, J., C. Möller, O. G. Isaksson, A. Nilsson, L. S. Mathews, and G. Norstedt. 1988. Regulation of insulin-like growth factor messenger RNA in ra growth plate by growth hormone. Endocrinology. 122:1515-1520.

22. Ito, H., M. Hiroe, Y. Hirata, T. Motoyoshi, S. Adachi, S. Masayoshi, A. Koike, A. Nogami, and F. Marumo. 1993. Insulin like growth factor-1 induces hypertrophy with enhanced expression muscle specific genes in cultured rat cardiomyocytes. Circulation, 87:1715-1721.

23. Fuller, J., J. R. Mynett, and P. H. Sugden. 1992. Stimulation of cardiac protein synthesis by insulin-like growth factors. Biochem. J. 282:85-90.

24. Wahlander, H., J. Isgaard, E. Jennische, and P. Friberg. 1992. Left ventricular insulin-like growth factor I increases in early renal hypertension. Hypertension (Dallas). 19:25-32.

25. Donahue, T. J., M. D. Dworkin, M. N. Lango, K. Fliegner, R. P. Lango, J. A. Benstein, W. R. Slater, and V. M. Catanese. 1994. Induction of myocardial insulin-like growth factor-I gene expression in left ventricular hypertrophy. Circulation. 89:799-809.

26. Powell-Braxton, L., P. Hollingshead, C. Warburton, M. Dowd, S. PittsMeek, D. Dalton, N. Gillett, and T. Stewart. 1993. IGF-1 is required for normal embryonic growth in mice. Genes \& Dev. 7:2609-2617.

27. Liu, J.-P., J. Baker, A. S. Perkins, E. J. Robertson, and A. Efstratiadis. 1993. Mice carrying null mutations of the genes encoding insulin-like growth factor I (Igf-1) and type 1 IGF receptor (Igf1r). Cell. 75:59-72.

28. Lei, L.-Q., S. Rubin, and M. C. Fishbein. 1988. Cardiac architectural changes with hypertrophy induced by excess growth hormone in rats. Lab. Invest. 59:357-362.

29. Merola, B., A. Cittadini, A. Colao, S. Longobardi, S. Fazio, D. Sabatini, L. Sacca, and G. Lombardi. 1993. Cardiac structural and functional abnormalitie in adult patients with growth hormone deficiency. J. Clin. Endocrinol. \& Metab. 77:1658-1661.

30. Amato, G., C. Carella, S. Fazio, G. La Montagna, A. Cittadini, D. Sabatini, C. Marciano-Mone, L. Sacca, and A. Bellastella. 1993. Body composition, bone metabolism, and heart structure and function in growth hormone (GH)-deficien adults before and after GH replacement therapy at low doses. J. Clin. Endocrinol. \& Metab. 77:1671-1676.

31. Theusen, L., S. E. Christensen, J. Weeke, H. Orskov, and P. Henningsen 1989. The cardiovascular effects of octreotide treatment in acromegaly: an echocardiographic study. Clin. Endocrinol. 30:619-625.

32. Chanson, P., J. Timsit, C. Masquet, A. Warnet, P.-J. Guillausseau, P. Birman, A. G. Harris, and J. Lubetzki. 1990. Cardiovascular effects of the somatostatin analog octreotide in acromegaly. Ann. Intern. Med. 113:921-925.

33. Shimatsu, A., and P. Rotwein. 1987. Mosaic evolution of the insulin-like growth factors: organization, sequence, and expression of the rat insulin-like growth factor I gene. J. Biol. Chem. 262:7894-7900.

34. Oh, B.-H., S. Ono, H. A. Rockman, and J. Ross, Jr. 1993. Myocardial hypertrophy in the ischemic zone induced by exercise in rats after coronary reperfusion. Circulation. 87:598-607.

35. Buñag, R. D., and J. Butterfield. 1982. Tail-cuff blood pressure measurement without external preheating in awake rats. Hypertension (Dallas). 4:898903.

36. Ono, S., V. Bhargava, S. Ono, L. Mao, G. Hagan, H. A. Rockman, and J. Ross, Jr. 1994. In vivo assessment of left ventricular remodeling after myocardial infarction by digital video-contrast angiography in the rat. Cardiovasc. Res. 28:349-357.

37. Indolfi, C., B. D. Guth, T. Miura, S. Miyazaki, R. Schulz, and J. Ross, Jr. 1989. Mechanisms of improved ischemic regional dysfunction by bradycardia. Studies on UL-FS 49 in swine. Circulation. 80:983-993.

38. Miura, T., S. Miyazaki, B. D. Guth, M. Kambayashi, and J. Ross, Jr. 1992. Influence of the force-frequency relation on left ventricular function during exercise in conscious dogs. Circulation. 86:563-571.

39. Dodge, H. T., H. Sandler, D. W. Ballew, and J. D. Lord. 1960. The use of biplane angiocardiography for the measurement of left ventricular volume in man. Am. Heart J. 60:762-776.

40. Breier, B. H., B. W. Gallaher, and P. D. Gluckman. 1991. Radioimmunoassay for insulin-like growth factor-I: solutions to some potential problems and pitfalls. J. Endocrinol. 128:347-357. 
41. Yin, R. C., H. A. Spurgeon, K. Rakusan, M. L. Weisfeldt, and E. G. Lakatta. 1982. Use of tibial length to quantify cardiac hypertrophy: application in the aging rat. Am. J. Physiol. 243:H941-H947.

42. Dobler, P. C., and M. S. Spach. 1987. Thin collagenous septa in cardiac muscle. Anat. Rec. 218:445-455.

43. MacKenna, D. A., and J. H. Omens. 1994. A semi-automated method for measuring collagen area fraction and size distribution using picrosirius red. Am. J. Cardiovasc. Pathol. 5:165-180.

44. Pickering, J. G., and D. R. Boughner. 1990. Fibrosis in the transplanted heart and its relation to donor ischemic time: assessment with polarized light microscopy and digital image analysis. Circulation. 81:949-958.

45. White, F. C., E. A. Breish, L. E. Nimmo, G. Witzel, and C. M. Bloor 1988. Regional capillary and myocyte density in normal and exercise trained male and female rat hearts. Am. J. Cardiovasc. Pathol. 2:247-253.

46. Chien, K. R., H. Zhu, K. U. Knowlton, W. Miller-Hance, M. van Bilsen T. X. O'Brien, and S. Evans. 1993. Transcriptional regulation during cardiac growth and development. Annu. Rev. Physiol. 55:77-95.

47. Sadoshima, J., U. Zu, H. S. Slayter, and S. Izumo. 1993. Autocrine release of angiotensin II mediate stretch-induced hypertrophy of cardiac myocytes in vitro. Cell. 75:977-984.

48. Rubin, S. A., P. Buttrick, A. Malhotra, S. Melmed, and M. C. Fishbein 1990. Cardiac physiology, biochemistry and morphology in response to excess growth hormone in the rat. J. Mol. Cell. Cardiol. 22:429-438.

49. Ballard, F. J., F. M. Tomas, L. C. Read, S. E. Knowles, P. C. Owens,
A. B. Lemmey, A. A. Martin, J. R. E. Wells, J. C. Wallace, and G. L. Francis. 1991. Effects of IGF-1 and IGF analogs on growth during catabolic states in rats In Modern Concepts of Insulin-Like Growth Factors. E. M. Spenser, editor. Elsevier Science Publishing Co., Inc., New York. 617-627.

50. Anversa, P., C. Beghi, Y. Kikkawa, and G. Olivetti. 1986. Myocardial infarction in rats. Infarct size, myocyte hypertrophy, and capillary growth. Circ. Res. 58:26-37.

51. Zimmer, H.-G., A. M. Gerdes, S. Lortet, and G. Mall. 1990. Changes in heart function and cell size in rats with chronic myocardial infarction. J. Mol. Cell. Cardiol. 22:1231-1243.

52. Ambler, G. R. B. M. Johnston, L. Maxwell, J. B. Gavin, and P. D. Gluckman. 1993. Improvement of doxorubicin induced cardiomyopathy in rats treated with insulin-like growth factor I. Cardiovasc. Res. 27:1368-1373.

53. Gay, R. G., S. Graham, M. Aguire, S. Goldman, and E. Morkin. 1988 Effects of 10- to 12-day treatment with L-thyroxine in rats with myocardial infarction. Am. J. Physiol. 255:H801-H806.

54. Litwin, S. E., T. E. Raya, P. G. Anderson, C. M. Litwin, R. Bresler, and S. Goldman. 1991. Induction of myocardial hypertrophy after coronary ligation in rats decreases ventricular dilatation and improves systolic function. Circulation. 84:1819-1827.

55. Omens, J. H., H. R. Rockman, and J. W. Covell. 1994. Passive ventricular mechanics in tight-skin mice. Am. J. Physiol. 266:H1-H8.

56. Wright, A. J. A., O. Hudlicka, and M. D. Brown. 1989. Beneficial effect of chronic bradycardial pacing on capillary growth and heart performance in volume overload heart hypertrophy. Circ. Res. 64:1205-1212. 